\title{
Литературоведение
}

\author{
УДК 821.161.1-32
}

\section{Е.А. Иваньиина}

\section{КОЛЕСО ФАБУЛЫ И ДВИЖЕНИЕ СЮЖЕТА: КАК РАБОТАЕТ МОТИВНЫЙ КОМПЛЕКС У А.П. ЧЕХОВА}

В статье рассматривается сюжетообразующий потенциал инвариантного чеховского шаблона, в котором задействованы парные персонажи - доктор и следователь. На примере нескольких текстов («Perpetuum mobile», «По делам службы», «Драма на охоте», «Следователь», «Палата №6») прослеживается, как работает этот шаблон в разных жанровых контекстах (романтическая новелла, святочный рассказ, детективная повесть) и как эти контексты пересекаются друг с другом. Общими для рассматриваемого ситуативного шаблона являются мотивы предчувствия и заколдованного круга, которые заряжены неоднозначной модальностью и пересекаются с мотивом театральности, который, в свою очередь, связан с профессиональной рефлексией, объединяющей фигуры врача, следователя и писателя. Особое внимание уделяется повести «Драма на охоте», которая актуализируется как метатекст, в котором - на фоне удвоения системы персонажей - образуется дополнительное смысловое измерение охоты как нарративной стратегии. Итоговыми текстами рассматриваемой группы можно считать рассказы «По делам службы» и «Палата №6», в которых через актуализированный мотивный комплекс осмысливается чувство долга и профессиональной вины.

Ключевые слова: мотивный комплекс, шаблон, доктор, следователь, предчувствие, охота, заколдованный круг, театральность.

DOI: $10.35634 / 2412-9534-2021-31-3-543-550$

Мотивный анализ как инструментарий литературоведения во многом обязан Б. Гаспарову, который понимает мотив как кросс-уровневую смыслоразличительную единицу текстообразования: в роли мотива может выступать «любой феномен, любое смысловое "пятно" - событие, черта характера, элемент ландшафта, любой предмет, произнесенное слово, краска, звук и т. д.; единственное, что определяет мотив, - его репродукция в тексте» [1, с. 30-31]. Мотив - «подвижный компонент, вплетающийся в ткань текста и существующий только в процессе слияния с другими компонентами. Ни характер мотива - его объем, "синтагматические" отношения с другими элементами, "парадигматический" набор вариантов, в которых он реализуется в тексте, - ни его функции в данном тексте невозможно определить заранее; его свойства вырастают каждый раз заново, в процессе самого анализа, и меняются с каждым новым шагом, с каждым изменением общей смысловой ткани» [1, с. 301]. Связи, из которых вырастает смысловая ткань текста, завязываются одновременно между многими разными его компонентами, по многим разным направлениям» [1, с. 300-301].

Теория мотива - дискуссионная проблема, в поле которой пересекаются интересы разных дисциплин. Для данной статьи, цель которой - проследить не отдельные мотивы, а их сочетаемость и валентность в чеховских сюжетах, релевантно именно гаспаровское определение мотива как повторяющегося «смыслового пятна», объективным доказательством существования которого являются его воспроизводимость и интертекстуальность, точнее, автоинтертекстуальность - повторяемость в пределах чеховского текста, понимаемого как динамическое художественное единство, основанное на тематическом единстве и общих приёмах выразительности.

В отличие от работ, в которых объектом рассмотрения является тот или иной «сквозной» мотив чеховской прозы [10], нас интересуют мотивные сращения, в которых реализуется специфика авторского поведения Чехова ${ }^{1}$, проявляющаяся в конвенциональности тех или иных мотивов или мотив-

\footnotetext{
${ }^{1}$ Авторское поведение - термин А.А. Фаустова. Говоря об общей стратегии работы Чехова с «чужими» текстами, А.А. Фаустов отмечает, что «литература оказывается у Чехова как бы раздёрганной на лоскутки, низведённой до отдельных, оторвавшихся от своих источников фраз, до смутного представления о находящихся на слуху героях (которые с лёгкостью уравниваются друг с другом), до школьного реквизита - одним словом, до социального антиквариата (больше похожего на беспорядочно сваленный хлам), который давно уже с реальностью никак не соприкасается и в силу этого делается годным разве лишь на то, чтобы реальность эту маскировать, фальсифицировать» [8, с. 11-12].
} 
ных комплексов, в их способности к приращению смысла, его инверсии или переформатированию.

Чехов - мастер комбинаторики, в художественной системе которого за нюансы смыслопорождения отвечают не отдельные мотивы, а мотивные комплексы, образующие как бы готовый сюжетный геном, способный разворачиваться в разных направлениях, варьироваться и «расти» по принципу гипертекста, связываясь с другими комплексами. Мотивный комплекс - инвариантное смысловое сращение, которое позволяет связывать тексты разной степени отдаленности ${ }^{2}$. В мотивном комплексе всегда будут определяться ядерные и периферийные мотивы, но в зависимости от широты привлекаемого чеховского материала и обнаружения новых вариантов искомого мотивного комплекса ценр и периферия будут перераспределяться: зачастую мотивы, которые кажутся периферийными, обнаруживаются в смежных мотивных комплексах и за счёт собственных семантических связей выводят к менее очевидным контекстам, которые могут разрушать интерпретационные ожидания. При этом валентность мотива возрастает и происходит его смысловая перекодировка. Другими словами, различные чеховские тексты интерпретируют и корректируют друг друга.

Сочетаемость мотивов, их взаимная обусловленность и связанность у Чехова - аспект, который далёк от исчерпанности. Зачастую тот мотив, который воспринимается как ядерный, является ситуативным шаблоном, запускающим колесо фабулы, а за разработку смыслов, то есть за движение сюжета, отвечают те детали, которые кажутся несущественными, «позиционными» ${ }^{3}$. Покажем это на примере одного ситуативного шаблона.

В чеховских рассказах несколько раз встречается пара: доктор и судебный следователь, едущие на вскрытие. Такова исходная ситуация рассказа «Perpetuum mobile» (1884). По дороге следователь предлагает заночевать у отставного генерала Ежова, где их ждут ужин и симпатичная вдовушка, которая жалуется доктору на бессонницу и намекает, что будет ждать его ночью у себя в комнате. «Вы на вскрытие едете? - начала хорошенькая вдовушка. - Вскрывать мертвеца? Ах! Какую надо иметь силу воли, какой железный характер, чтобы не морщась, не мигнув глазом, заносить нож и вонзать его по рукоятку в тело бездыханного человека. Я, знаете ли, благоговею перед докторами» [9, т. 2, с. 324-325]. Доктор не понимает намёков, зато их хорошо понимает следователь, который сам хочет воспользоваться бессонницей вдовы. Доктор пытается потушить пыл следователя и не пустить его к даме. Разгорается ссора, которая в романтическом сюжете непременно переросла бы в дуэль: доктор ведёт себя так, как будто он защищает честь женщины, а следователь в ответ оскорбляет его, называя канальей. Однако вместо того, чтобы вызвать обидчика на поединок, как это было бы в жанре романтической новеллы, доктор говорит следователю, что не может оставаться с ним в одном доме и уезжает, а так как своих лошадей у следователя нет, то он тоже уезжает с доктором. Ничего более нелепого и представить себе нельзя. Через три дня, когда душевное равновесие доктора восстанавливается, к нему домой приезжает всё тот же следователь. Происходит примирение, и, выпив квасу, парочка снова отправляется на вскрытие всё того же унтер-офицерского трупа. Однако по дороге, возле трактира, они видят генеральскую тройку и не могут проехать мимо, не повидавшись со старыми знакомыми. «На вскрытие всё ездим, да никак не доедем. В заколдованный круг попали <..>», - отвечают они на вопрос Ежова о цели их поездки [9, т. 2, с. 329]. Оказывается, что и сам Ежов попал в тот же «заколдованный круг»: он со своим приятелем, прокурором, третий день не может доехать до съезда. Начавшаяся карточная игра, наличие женщины и приезд исправника обещают, что и вскрытие, и съезд будут ждать ещё какое-то время.

В рассказе пародируются шаблоны романтической новеллы. Меланхолический доктор одержим предчувствиями. «Меня гнетет какое-то странное, тяжелое предчувствие. Вот-вот, кажется мне, стрясется надо мной какое-то несчастие. А я верю в предчувствия и... жду. Всё может случиться. Трупное заражение... смерть любимого существа...» [9, т. 2, с. 323] - эти опасения он повторяет дважды, как заученную роль. Однако предчувствия не сбываются, как не сбывается ожидаемая дуэль. Ситуация грозит дурной бесконечностью. И предчувствия, и заколдованный круг, и страстная вдова, и дуэль, и мертвое тело - всё это оказывается виртуальным романтическим реквизитом, подсвечивающим банальную прозу жизни. Особенность рассказа в том, что в нём ничего не происходит: служебная ситуация, обязательными элементами которой являются доктор, судебный следователь и дожидающийся вскрытия труп, не завершается. Сюжет рассказа построен как минус-приём: нагнетание романти-

${ }^{2}$ Для сравнения см. определение М.Б. Лоскутниковой: «Мотивный комплекс - телеологически выверенная автором совокупность значимых дя него тем, как правило, лексически маркированных <..> Особенностью чеховских мотивных комплексов является их окрашенность разнооттеночной драматической иронией» [6, с. 21].

${ }^{3}$ О позиционном стиле, который является противоположностью композиционного, см.: [2]. 
Колесо фабулы и движение сюжета: как работает мотивный комплекс у А.П. Чехова

ческих мотивов разрешается в анти-романтическом духе. Однако можно рассматривать «Ретреtuum mobile» как двигатель, запускающий серию сюжетов с тем же кругом участников, как «колесо» последующих фабул. Собственно это и есть ситуативный шаблон.

В романтической новелле труп, не дождавшись освидетельствования, нашёл бы случай напомнить о себе, например, явился бы меланхолическому доктору во сне. Подобное происходит в позднем рассказе «По делам службы» (1899), но не с доктором. Снова та же ситуация: доктор и судебный следователь едут на вскрытие. Умерший - земский страховой агент, застрелившийся в земской избе. Вскрытие необходимо, чтобы исключить убийство. С момента смерти идёт третья ночь («Народ очень беспокоится, ваше высокоблагородие, уж третью ночь не спят», - говорит встречающий приехавших сотский [9, т. 10, с. 87]). Дополнительным обстоятельсвом, удлинившим дорогу врачу и следователю, здесь становится метель, которая берёт на себя функцию «заколдованного круга»: «По дороге их захватила метель, они долго кружили и приехали к месту не в полдень, как хотели, а только к вечеру, когда уже было темно» [9, т. 10, с. 86]. Приехавшим предстоит заночевать в избе по соседству с мёртвым телом, и эта перспектива, разумеется, не может их радовать. Доктор в досаде упрекает покойника: «Стреляться в земской избе - как это бестактно!» [9, т. 10, с. 87]. Завязывается разговор о самоубийцах Доктор резонёрствует, потом уезжает ночевать к знакомому за три версты. Пока он отсутствует, следователь выслушивает рассказ сотского Ильи Лошадина и вспоминает, при каких обстоятельствах видел покойного Лесницкого. Илья Лошадин - «свёрнутый» в имя персонажа лошадиный мотив (Илья имя пророка, правящего лошадьми). Неожиданное воспоминание о том времени, когда застрелившийся был жив (аналог путешествия сквозь время), метель и сновидение, в котором следователь видит покойника (вместе с сотским Лошадиным) - знаки святочного текста, хотя формально «По делам службы» не принадлежит к жанру святочного рассказа ${ }^{4}$. Неслучайно в рассказе Лошадина о службе здесь упоминается Пасха (симметричный праздник): «У людей праздник, а я всё хожу. На дворе Святая, в церквах звон, Христос воскресе, а я с сумкой» [9, т. 10, с. 89]. Сотский становится своеобразным духом Рождества: он будит совесть следователя и вызывает в нём приступ гуманности, который уравнивает живых и мёртвых, конных и пеших, занимающих высокое и низкое положение в служебной иерархии. Сначала следователь тешит себя мыслью, что когда-нибудь вырвется из этих мест в Москву, где настоящие люди живут настоящей жизнью. Под вой метели он засыпает, но его будит доктор, который приехал забрать его с собой на ночлег. Однако и в уютном доме, вдали от покойника, следователь не может заснуть: впечатления дня связываются у него одной общей идеей, и он видит сон, в котором покойник и сотский идут в метели, неся на себе тяжесть не только своей, но и его жизни: «Старик был похож на колдуна в опере, и оба в самом деле пели, точно в театре: - Мы идем, мы идем, мы идем... Вы в тепле, вам светло, вам мягко, а мы идем в мороз, в метель, по глубокому снегу... Мы не знаем покоя, не знаем радостей... Мы несем на себе всю тяжесть этой жизни, и своей, и вашей... У-у-у! Мы идем, мы идем, мы идем...» $[9, \text { т. 10, с. 99 }]^{5}$. Сотский, который и в обыденной жизни является связным, во сне связывает следователя с покойным; явление покойника с сотским театрально, неслучайно здесь повляется сравнение с оперой. Оперный мотив возникает и во второй части рассказа, которая разворачивается в доме Тауница, дочки которого исполняют перед гостями дуэт из «Пиковой дамы». Участвуя в домашнем весельи у Тауница, следователь не верит сказочному превращению (перемене декораций), которое возможно «на протяжении каких-нибудь трех верст, одного часа» и думает: «не сон ли всё это?» [9, т. 10, с. 97]. Ещё на сутки из-за погоды доктор и следователь задерживаются в гостях, а потом едут на вскрытие, которого, как благодеяния, ожидают крестьяне, всё это время не спящие из-за страха перед находящимся поблизости мертвецом.

«Perpetuum mobile» и «По делам службы» - крайние варианты фабульного шаблона: первый рассказ интересен своим нереализованным сюжетным потенциалом (можно сказать, что это и есть

\footnotetext{
${ }^{4}$ Те же мотивы без формальной привязки к святкам встречаются в рассказе Чехова «Воры» [8, с. 9-10].

${ }^{5}$ Следователю Лыжину в этом рассказе достается роль «пробужденного» интеллигента, в то время как сотский Лошадин является воплощением совести. По мнению А. Иваницкого, в рассказе «По делам службы» отражен «народнический» концепт службы, видящий в народе источник подлинной мудрости и морали, к которой интеллигент-служитель должен приобщиться [3, с. 49-50]. Другая - «западническая» - версия того же концепта исходит из убеждения, что народ нужно поднимать до уровня интеллигенции. Отношения интеллигента с совестью составляют и сюжет рассказа «Палата № 6», однако здесь доктор отказывается прислушаться к совестиГромову, хотя и видит в нем единственного равного собеседника. Совесть существует как бы отдельно от Рагина до тех пор, пока они не оказываются в одной палате.
} 
фабула в чистом виде); второй рассказ является итоговым, в нём фабула хотя и не завершена (дело, ради которого едут персонажи, не сделано), но сюжет разработан и доведен до ожидаемого финала, которым является проснувшаяся совесть следователя (являющаяся в облике сотского Лошадина). Посмотрим, что представляют собой промежуточные варианты сюжетов, вращающихся на том же фабульном «колесе».

Ту же пару персонажей мы видим и в «Драме на охоте» (1884). «Очень хороший малый», - говорит о докторе Вознесенскм его приятель, следователь Зиновьев. Однако о самом следователе сказать такого нельзя. Двое приятелей следователя - кутила-граф Карнеев и доктор Вознесенский - как две стороны его натуры, о которой доктор говорит так: «Дай бог, чтоб я заблуждался, но мне кажется, что вы немножко психопат. У вас иногда, вопреки воле и направлению вашей хорошей натуры, вырываются такие желания и поступки, что все знающие вас за порядочного человека становятся в тупик... Диву даешься, как это ваши высоконравственные принципы, которые я имею честь знать, могут уживаться с теми вашими внезапными побуждениями, которые в исходе дают кричащую мерзость!» [9, т. 3, с. 299] Доктор оказывается абсолютно прав. Взывая к лучшим чувствам Зиновьева, уговаривая его жениться на Наденьке Калининой, он до конца остаётся в неведении, что его друг, судебный следователь, - убийца Оленьки Урбениной, тело которой они вместе вскрывают.

Мотив «двое в одном» проявляется и в раздвоении следователя на персонажа своей повести (Зиновьев) и её автора (Камышев). Главное качество, объединяющее эти две фигуры - лживость, проявляющаяся через театральность поведения. Актёрство в контексте данной повести становится синонимом лжи. «Убийца вы и есть <..> и даже скрыть этого не можете: в романе проврались, да и сейчас плохо актерствуете» $[9$, т. 3, с. 40], - говорит Камышеву прочитавший его повесть редактор.

В повести Камышева его автореферентный персонаж - Зиновьев - актёрство приписывает Урбенину, который становится во всей этой истории козлом отпущения. Написание бывшим следователем повести об убийстве - с одной стороны, создание себе своеобразного алиби, с другой стороны признание вины, так как подлинный убийца здесь вычисляется (указание на подлинного убийцу и является завершением драмы на охоте). Очень точно пишет о мотивах Камышева Р. Назиров: «Пером Камышева водило тщеславие, он хвастливый преступник, fanfaron de vice, как говорят французы, он хотел бы и похвастаться своим злодеянием, и не дать себя поймать. <..> Рукопись Камышева фальшивая исповедь. Эту форму позже использовала Агата Кристи <...>» [7, с. 165]. Роль подлинного следователя здесь выпадает редактору, которому Камышев приносит свою вещь, и в этой роли редактор подобен Порфирию Петровичу из «Преступления и наказания», с той разницей, что Порфирий вычислил убийцу заранее, а редактор становится следователем поневоле («Мне казалось, что я, не судебный следователь и еще того менее не присяжный психолог, открыл страшную тайну одного человека, тайну, до которой мне не было никакого дела... Я ходил по террасе и убеждал себя не верить своему открытию...» [9, т. 3, с. 245-246]). Однако тот же редактор оказывается не только в роли следователя, но и в роли психолога, так как медицинский аспект рассказанной истории не менее важен, чем уголовный. Главный герой «Драмы на охоте» напоминает стивенсоновского Джекила и Хайда: когда он психопат, он способен на самые страшные поступки, о которых в светлой фазе как будто бы забывает. Однако повесть Стивенсона появится чуть позже чеховской «Драмы на охоте» (в Лондоне она впервые будет опубликована в 1886 году). Кроме того, чеховская пара «доктор - следователь» напоминает знаменитую пару «Холмс - Уотсон», с которой читатель - не только русский, но и английский - тоже познакомится чуть позже. Так что Чехов не только использует старые литературные клише, но и соответствует актуальным для своего времени читательским ожиданиям.

O «Драме на охоте» написано немало: в ней справедливо видят множество литературных аллюзий [7], в частности, пародию на детективный роман (эти адреса - Габорио, Шкляревский - названы самим пишущим, то есть Камышевым) [5] и на Достоевского [7; 4]. Но можно смотреть на «Драму на охоте» и шире - как на метатекстуальную новеллу, в которой дезавуируется литературная «кухня». При такой переакцентировке основное внимание будет направлено не на вопрос «Кто убил?!», как в детектином сюжете, а на соотнесение события и рассказа о нём, драмы-происшествия и драмы-текста. В этом случае роль следователя и доктора отводится не только редактору, но и читателю, который должен разобраться с «трупом» рассказанной истории. Неслучайно чтение становится в «Драме на охоте» частью изображаемой реальности: читающими персонажами здесь показаны и слуга следователя Поликарп, и Оленька, и граф. Проекцией затекстового читателя, чувства которого якобы щадит Камышев, является его друг доктор Вознесенский. Однако именно доктор знает о следователе то, о чём не догадываются другие - о тайне его натуры, о её темной, инстинктивной стороне. 
Колесо фабулы и движение сюжета: как работает мотивный комплекс у А.П. Чехова

Самое интересное в «Драме на охоте» - драматургия нарратива, то есть то, как играет Камышев с читателем, как формирует его ожидания, как в этой игре он использует литературные шаблоны, о которых сам говорит редактору: «Повесть моя написана по шаблону бывших судебных следователей, но... в ней вы найдете быль, правду... Всё, что в ней изображено, всё от крышки до крышки происходило на моих глазах... Я был и очевидцем и даже действующим лицом» [9, т. 3, с. 244].

У автора «Драмы на охоте» шаблонов больше, чем у его героя. Но в каком-то - разумеется, сугубо литературном - смысле Камышев - авторский двойник. Двойничество Камышева и Зиновьева удваивается двойничеством Камышева и автора. Жизнь Зиновьева как изображенного двойника Камышева в написанном им романе подобна охоте; охота здесь - метафора вожделения, высвобождения инстинктов, которые в другое время вуалируются чрезмерной театрализацией поведения; «зайцы»Оленька Урбенина и Наденька Калинина; но и сами «зайцы» являются ловцами (женщины расставляют сети на мужчин).

Страгия автора по отношению к читателю тоже может быть интерпретирована как охота: если в процессе жизни-охоты мы наблюдаем, как мужчины охотятся на женщин, а женщины на мужчин, то в процессе нарративной охоты «дичью» становится читатель, для которого с самых первых фраз расставляются приманки и ловушки. К таким ловушкам относятся многократно упоминаемые предчувствия и nриметьl, расставленные в рассказе с подчеркнутой театральностью. Чего стоит одна только первая фраза, с которой начинается повесть Камышева: «Муж убил свою жену! Ах, как вы глупы! Дайте же мне наконец сахару!» [9, т. 3, с. 246]. Эта реприза, являющася «зерном» сюжета и содержащая внутреннее противоречие (первое предложение объявляет виновника, второе «даёт по морде» доверчивому читателю, третье обозначает цель рассказа - получение награды вместо наказания), будет затем много раз повторена попугаем Иваном Демьянычем, который в финале будет застрелен Зиновьевым, став его четвёртой серийной жертвой (до этого были ударенный веслом по голове - не насмерть - мужик Иван Осипов, кулик и Оленька). Попугай в рассказанной истории становится псевдорезонёром и как бы сообщником Камышева; это ещё один - пародийный - двойник Камышева-нарратора, который, будучи преступником, страхуется разными «уликами», которые он - руками Зиновьева - подсовывает невиновным, в том числе Урбенину, ревность которого он разыгрывает как один из козырей. Весь рассказ Зиновьева раскручивается как сбывшееся предсказание попугая, и в финале Зиновьев предъявляет Урбенину обвинение, которое превращает попугая в пророка. Так замыкается один круг.

В финале большой повести, включающей разбор рукописи редактором, обвинение в убийстве переадресуется Камышеву. Замыкается второй круг. Такая переадресация имеет литературный смысл: убийцей объявляется автор. Охота переосмысливается как метатроп, объединяющий изображаемые события и событие рассказывания и связывающий автора с читателем как охотника с дичью. Это заставляет нас по-новому посмотреть на сюжеты, в мотивный комплекс которых входит охота, но это уже предмет отдельного разговора.

Пародийная реплика редактора в «Драме на охоте» («Так вы же и убили») отсылает к реплике Порфирия Петровича в «Преступлении и наказании» («Вы и убили-с...») и указывает на перемену ролей: следователь объявляется убийцей. Несколько в другом ракурсе следователь-убийца предстёт в рассказе «Следователь» (1887). «Уездный врач и судебный следователь ехали в один хороший весенний полдень на вскрытие» [9, т. 6, с. 186], - так остроумно начинается рассказ, и это нарративное остроумие уже само по себе становится предвестником (как и начальная реплика попугая в «Драме на охоте»). Только на сей раз о предчувствиях размышляет следователь: «В природе есть очень много загадочного и темного, но и в обыденной жизни, доктор, часто приходится наталкиваться на явления, которые решительно не поддаются объяснению. Так, я знаю несколько загадочных, странных смертей, причину которых возьмутся объяснить только спириты и мистики, человек же со свежей головой в недоумении разведет руками и только. Например, я знаю одну очень интеллигентную даму, которая предсказала себе смерть и умерла без всякой видимой причины именно в назначенный ею день. Сказала, что умрет тогда-то, и умерла» $[9$, т. 6, с. 186]. Доктор возражает: по его мнению, нет действия без причины. Он предполагает, что женщина умерла не от предчувствия, а от отравления морфием, а причину отравления он видит в измене мужа. Вопросы, которые доктор задаёт следователю, продиктованы здравым смыслом. Логика вопросов проявляет мотивы самоубийства женщины, которых следователь не хотел видеть раньше, потому что женщина была его женой. Врач становится здесь на позицию следователя, он «вскрывает» - за отсутствием «трупа» - истинные мотивы поступка «предсказательницы», и итог расследования действует на виновника самоубийства отравляюще. Ему удобней было бы думать, что 
«крайний» в этой истории не он («Мне и в голову не приходила мысль о такой возможности... Да и к тому же... он не так уж виноват, как кажется... Изменил как-то странно, сам того не желая <...>» $[9$, т. 6 , с. 189]), а пресловутое предчувствие, которым жена прикрывала готовящуюся месть. Логика вопросов доктора - логика совести следователя, которая постепенно просыпается, но не так, как следовало бы («Боже мой, если ваше предположение справедливо, то ведь это... это жестоко, бесчеловечно! Отравила себя, чтобы казнить этим другого! Да разве грех так велик! Ах, боже мой! И к чему вы мне подарили эту проклятую мысль, доктор!» [9, т. 6, с. 190]) и в конце концов приводит к признанию («Это я рассказывал вам про свою жену, про себя. О, боже мой! Ну, я виноват, я оскорбил, но неужели умереть легче, чем простить! Вот уж именно бабья логика, жестокая, немилосердная логика. О, она и тогда при жизни была жестокой! Теперь я припоминаю! Теперь для меня всё ясно!» [9, т. 6, с. 190]). Вместо раскаяния обвинение переадресовывается следователем его покойной жене. Этот тот случай, когда персонаж не внемлет голосу совести (в роли которой выступает доктор). Но право последнего слова оставила за собой умершая жена. Круг замкнулся обвинением неверного мужа.

Поведение жены, которое анализирует доктор, подобно поведению рассказывающего свою историю Камышева. Врач же в этом рассказе подобен редактору в «Драме на охоте»: он тоже оказывается невольно втянутым в чужую тайну и разгадывает её. Рассказ следователя - аналог повести Камышева, который рассказывает о сбывшемся предчувствии одной женщины (вокруг Оленьки в повести намеренно выстраивается «навес» из предчувствий). В обоих случаях следователи утаивают правду и создают себе алиби, так как оба являются и ощущают себя убийцами. При этом оба рассказчика собственных историй прикрываются литературным шаблоном: разница в том, что в «Следователе» это шаблон романтической новеллы, тогда как в «Драме на охоте» в качестве шаблона названы Габорио и Шкляревский, а граф в письме называет своего приятеля Лекоком [9, т. 3, с. 249].

В заколдованный круг попадает и доктор Рагин. «Болезнь моя только в том, что за двадцать лет я нашел во всем городе одного только умного человека, да и тот сумасшедший. Болезни нет никакой, а просто я попал в заколдованный круг, из которого нет выхода» [9. Т. 8. С. 118]. О заколдованном круге Рагин упоминает трижды. В «Палате № 6» (1892) заколдованный круг - жизнь, которую резонёрствующий Рагин называет ловушкой. Рагин мог бы сойти за пророка, однако это не так. Он псевдорезонёр и в этом качестве подобен - как ни странно это прозвучит - застреленному хозяином попугаю Ивану Демьянычу из «Драмы на охоте». Сумасшедший Громов - совесть доктора, которую он случайно находит в качестве единственного приятного собеседника в палате для душевнобольных, но доводов которой не хочет принимать на свой счёт. Между тем уклонение от своих профессиональных обязанностей достигает у Рагина крайней степени: его пациенты совсем его не интересуют, включая Громова, в палату к которому Рагин ходит как в театр. В прошлом Громов - судебный пристав и губернский секретарь. Эта пара персонажей похожа на едущих на вскрытие доктора и судебного следователя. Трупом здесь становится сам Рагин. Здесь тоже имеет место удвоение ситуации: коллеги ведут себя по отношению к Рагину так же, как он ведет себя по отношению к пациентам: и Рагин, и его коллеги используют своё служебное положение в личных интересах (пусть интерес Рагина к Громову и не связан с корыстью). Михаил Аверьяныч так же использует Рагина, как Рагин - Громова.

Между всеми названными текстами существует связь, эксплицированная в мотивном комплекce, едва намеченном в рассказе «Perpetuum mobile» (1884): в этот комплекс входят мотивы заколдованного круга и предчувствия. Финальным рассказом в этой «серии» является хронологически самый поздний рассказ «По делам службы» (1899). Между этими «крайними» текстами в том же смысловом поле службы расположены «Драма на охоте» (1884), «Следователь» (1887) и «Палата № 6» (1892). В рамках этой конфигурации ставится вопрос о профессиональном долге, в рефлексию о котором втянуты доктор, писатель и следователь - персонажи, представляющие различные авторские ипостаси. Внутри этого смыслового поля за счёт варьирования одних и тех же мотивов содаётся напряжение, деформирующее «втянутых» в него персонажей: они меняются ролями, отклоняются от заданной автором нравственной траекории, но сама траектория, подобно заколдованному кругу, остаётся неизменной.

\section{СПИСОК ИСТОЧНИКОВ И ЛИТЕРАТУРЫ}

1. Гаспаров Б.М. Литературные лейтмотивы. Очерки по русской литературе XX века. М.: Наука, 1993.304 с.

2. Зубарева В.К. Позиционный стиль Чехова и школа Захарьина // Inskrypcje. Półrocznik, R. VIII 2020, z. 1 (14), pp. 15-20. 
3. Иваницкий А.И. Символика «службы» у Чехова и ее смысловые продолжения // Филологические записки: Вестник литературоведения и языкознания. Вып.30. Воронеж: Воронежский государственный университет, 2020. C. $45-54$

4. Кибальник С.А. Чехов и русская классика: Проблемы интертекста. Статьи, очерки, заметки. С-Пб.: ИД Петрополис, 2015. $314 \mathrm{c}$.

5. Кибальник С А. «Судебный следователь» в русской детективной литературе 1860-1880-х гг. От Александра Шкляревского до Чехова // Вестник РУДН. Серия: Литературоведение. Журналистика. 2017. Т. 22, № 3. C. 384-397.

6. Лоскутникова М.Б. Система мотивов в рассказе Чехова «Бабье царство» (в контексте изображения женских характеров в прозаических произведениях писателя второй половины 1880-х - начала 1900-х годов) // Inskrypcje. Półrocznik, R. VIII 2020, z. 1 (14), pp. 21-31.

7. Назиров Р.Г. Достоевский и Чехов: преемственность и пародия // Назиров Р.Г. Русская классическая литература: сравнительно-исторический подход. Исследования разных лет: сборник статей. Уфа: РИО БашГУ, 2005. C. $159-168$.

8. Фаустов А.А. Авторское поведение А.П. Чехова и проблемы литературной генеалогии // Филологические записки: Вестник литературоведения и языкознания. Вып. 30. Воронеж: Воронежский государственный университет, 2020. С. 6-24.

9. Чехов А.П. Полное собрание сочинений и писем: в 30 т. Сочинения: В 18 т. М.: Наука, 1974-1982. Т. 2: [Рассказы. Юморески], 1883-1884. 1975. 584 с.; Т. 3: [Рассказы. Юморески. «Драма на охоте».], 1884-1885. 1975. 624 с.; Т. 8: [Рассказы. Повести], 1892-1894. 1977. 528 с.; Т. 10: [Рассказы, повести], 1898-1903. 1977. 496 с. 10. Шехватова А.Н. Мотив в структуре чеховской прозы: автореф. дис. ... канд. филол. наук. СПб., 2003. 26 с.

Поступила в редакцию 21.09.2020

Иваньшина Елена Александровна, доктор филологических наук, профессор кафедры теории, истории и методики преподавания русского языка и литературы ФГБОУ ВО «Воронежский государственный педагогический университет» 394024, Россия, г. Воронеж, ул Ленина, 86

E-mail: sergiencou@yandex.ru

\section{E.A. Ivanshina \\ FABULA WHEEL AND PLOT MOVEMENT: HOW THE MOTIVIC COMPLEX WORKS IN A.P. CHEKHOV}

DOI: $10.35634 / 2412-9534-2021-31-3-543-550$

The article considers the plot-forming potential of the invariant Chekhov pattern, which involves paired characters - the doctor and the investigator. Using the example of several texts ("Perpetuum mobile", "On Official Duty", "Drama on the hunt", "Investigator", "Ward No. 6"), we can see how this template works in different genre contexts (romantic novel, Christmas story, detective story) and how these contexts intersect with each other. Common to consider situational template are the motives of feeling and the vicious circle, which charged a mixed modality and intersect with the motive of theatricality, which, in turn, is associated with professional reflection, combining the figures of doctor, investigator and writer. Special attention is paid to the story "Drama on the Hunt", which is updated as a metatext, in which - against the background of the doubling of the character system - an additional semantic dimension of hunting as a narrative strategy is formed. The final texts of the group under consideration can be considered the stories "On Official Duty" and "Ward No. 6", in which a sense of duty and professional guilt is comprehended through an updated motivational complex.

Keywords: motivic complex, pattern, doctor, investigator, premonition, hunting, vicious circle, theatricality.

\section{REFERENCES}

1. Gasparov B.M. Literaturnye lejtmotivy. Ocherki po russkoj literature XX veka [Literary leitmotives. Essays on Russian literature of the twentieth century] M.: Nauka [The science], 1993. 304 s. (in Russian)

2. Zubareva V.K. Pozicionnyj stil' Chekhova i shkola Zahar'ina [Chekhov's Positional Style and the Zakharyin School] // Inskrypcje. Półrocznik [Inscriptions. Semi-annual ], R. VIII 2020, z. 1 (14), pp. 15-20. (in Russian)

3. Ivanickij A.I. Simvolika «sluzhby» u Chekhova i ee smyslovye prodolzheniya [The symbolism of Chekhov's" service " and its semantic continuations ] // Filologicheskie zapiski: Vestnik literaturovedeniya i yazykoznaniya [Philological Notes: Bulletin of Literary Studies and Linguistics. ]. Vyp.30. Voronezh: Voronezhskij gosudarstvennyj universitet [Voronezh State University ], 2020. S. 45-54. (in Russian) 
4. Kibal'nik S.A. Chekhov i russkaya klassika: Problemy interteksta. Stat'i, ocherki, zametki [Chekhov and the Russian Classics: Problems of Intertext. Articles, essays, notes]. S-Pb: ID Petropolis, 2015. 314 s. (in Russian)

5. Kibal'nik S.A. «Sudebnyj sledovatel'» v russkoj detektivnoj literature 1860-1880-h gg. Ot Aleksandra Shklyarevskogo do Chekhova ["The Forensic investigator" in the Russian detective literature of the 1860s-1880s. From Alexander Shklyarevsky to Chekhov] // Vestnik RUDN. Seriya: Literaturovedenie. Zhurnalistika [Bulletin of the Peoples ' Friendship University of Russia. Series: Literary Studies. Journalism]. 2017. T.22. №3. S. 384-397. (in Russian)

6. Loskutnikova M.B. Sistema motivov v rasskaze Chekhova «Bab'e carstvo» (v kontekste izobrazheniya zhenskih harakterov v prozaicheskih proizvedeniyah pisatelya vtoroj poloviny 1880-h - nachala 1900-h godov) [The system of motifs in Chekhov's short story "Babye Tsardom" (in the context of the depiction of female characters in the writer's prose works of the second half of the 1880s-early 1900s)] // Inskrypcje. Półrocznik [Inscriptions. Semi-annual], R. VIII 2020, z. 1 (14), pp. 21-31. (in Russian)

7. Nazirov R.G. Dostoevskij i Chekhov: preemstvennost' i parodiya [Dostoevsky and Chekhov: Continuity and parody] // Nazirov R.G. Russkaya klassicheskaya literatura: sravnitel'no-istoricheskij podhod. Issledovaniya raznyh let: sbornik statej [Russian classical literature: a comparative-historical approach. Studies of different years: a collection of articles]. Ufa: RIO BashGU, 2005. S. 159-168. (in Russian)

8. Faustov A.A. Avtorskoe povedenie A.P. Chekhova i problemy literaturnoj genealogii [The author's behavior of A.P. Chekhov and the problems of literary genealogy] // Filologicheskie zapiski: Vestnik literaturovedeniya i yazykoznaniya [Philological notes: Bulletin of Literary Studies and Linguistics]. Vyp. 30. Voronezh: Voronezhskij gosudarstvennyj universitet [Voronezh State University], 2020. S. 6-24. (in Russian)

9. Chekhov A.P. Polnoe sobranie sochinenij i pisem [Complete works and letters ]: V 30 t. Sochineniya [Essays ]: V 18 t. M.: Nauka [The science], 1974-1982. T. 2: [Rasskazy. Yumoreski [Stories. Humoreski ]], 1883-1884. 1975. 584 s.; T. 3: [Rasskazy. Yumoreski. «Drama na ohote» [Stories. Humoreski. "Drama on the hunt"]], 1884-1885. 1975. 624 s.; T. 8: [Rasskazy. Povesti [Stories. Novellas]], 1892-1894. 1977. 528 s.; T. 10: [Rasskazy, povesti [Stories. Novellas], 1898-1903. 1977. 496 s. (in Russian)

10. Shekhvatova A.N. Motiv v strukture chekhovskoj prozy: avtoreferat dis. ... kand. Filol. nauk [Motif in the structure of Chekhov's Prose: Abstract of Thesis of Candidate of Philological Sciences]. SPb., 2003. 26 s. (in Russian)

Received 21.09.2020

Ivanshina E.A., Doctor of philology, Associate Professor

at Department of theory, history and method of studying Russian and Literature

Voronezh State Pedagogical University

Lenina st., 86, Voronezh, Russia, 394024

E-mail: sergiencou@yandex.ru 